\title{
Reformas Liberalizantes e Aprovação Presidencial: A Politização dos Debates da Política Econômica no Brasil*
}

\author{
Andy Baker
}

\begin{abstract}
A o anunciar o plano de ajuste do governo, logo após sua posse, em janeiro de 1990, o presidente Fernando Collor de Mello (1990-1992) marcou o início de mudanças profundas na estrutura da economia brasileira. Seguiu-se, nos anos 90, uma onda de reformas (privatizações, liberalização do comércio, reformas administrativa e previdenciária) que reverteu, em menos de uma década, a estratégia de desenvolvimento via Estado, responsável pelo rápido crescimento econômico do Brasil no pós-30. O fato de essas reformas terem vindo na esteira da crise econômica dos anos $80 \mathrm{fez}$ com que fossem, também, parcialmente responsáveis pela continuidade da montanha-russa econômica. Uma profunda recessão ocorreu em 1991, seguida de uma explosão de consumo que durou três anos, a partir de 1994, e que resultou em uma crise de desemprego nos anos de 1998 e 1999. Além do impacto econômico, as reformas liberalizantes estruturaram, na nova democracia, um conflito de elites em torno da ques-
\end{abstract}

\footnotetext{
*Agradeço a Henrique Carlos de Oliveira de Castro, Isabel Castro, Michele Claibourn, Kenneth Greene, Leigh Payne e Corrie Potter e Lúcio Rennó pelos comentários construtivos. Também agradeço a Eduardo Schumacher, do The Wall Street Journal Americas, pelo fornecimento de dados e a Leany Barreiro de S. Lemos pela tradução do original em inglês "Free-Market Reform and Presidential Approval: The Politicization of Economic Policy Debates in Brazil".
}

DADOS - Revista de Ciências Sociais, Rio de Janeiro, Vol. 45, nำ1, 2002, pp. 77 a 98. 
tão legislativa. No Congresso Nacional, uma pequena mas unida esquerda opôs-se à nova política de livre mercado, defendida pelas forças mais amplas e heterogêneas de centro e de direita, tendo sido, inclusive, conduzidas por dois presidentes de centro-direita (Limongi e Figueiredo, 1995; Mainwaring, Meneguello e Power, 2000).

Dados a profundidade e o impacto dessas reformas e o fato de constituírem-se no principal foco do conflito político da elite brasileira, seria inusitada qualquer afirmação de que o eleitorado brasileiro não tem atitudes politizadas em relação à agenda de reforma neoliberal. Até o momento, entretanto, especialistas têm argumentado que as opiniões quanto à política econômica não influenciam nem o comportamento político nem a avaliação política feita pelo eleitorado - não influenciam, e.g., a identificação partidária, a determinação do voto ou os níveis de satisfação com o presidente. A prevalência do clientelismo nas relações Estado-sociedade e o nível educacional comparativamente baixo do eleitorado brasileiro levaram estudiosos a concluir que os eleitores brasileiros não são tão racionais quanto aqueles das democracias avançadas. Neste artigo, trago evidências de que os brasileiros politizam sim os debates sobre política econômica. Dados de um survey realizado em janeiro de 1998 demonstram que as atitudes do eleitorado com relação à privatização, investimento estrangeiro e liberalização do mercado influenciaram a avaliação presidencial de Fernando Henrique Cardoso.

\section{CONCEITOS PREDOMINANTES SOBRE O COMPORTAMENTO POLÍTICO BRASILEIRO}

Os primeiros estudos sobre opinião pública e comportamento eleitoral nos Estados Unidos quebraram o velho mito da existência de um cidadão democrático. Os trabalhos realizados pelas universidades de Columbia e de Michigan nas décadas de 40 e 50 descrevem um cidadão que contrasta nitidamente com o conceito tradicional posto pela teoria democrática (Campbell et alii, 1960; Lazarsfeld, Berelson e Gaudet, 1944). Em vez de cidadãos conscientes, preocupados com os debates políticos, verificou-se que a maioria dos americanos ignorava esses debates. No lugar de eleitores que acompanhavam o desempenho e as ações dos seus representantes no Congresso, percebeu-se que a maioria deles sequer sabia o nome dos senadores eleitos. E, no lugar de cidadãos que escolhiam os candidatos conforme suas posições políticas, os estudos encontraram pessoas votando baseadas na sua 
identidade de grupo, seguindo o critério de religião, classe, raça ou partido político (Campbell et alii, 1960; Converse, 1964; Berelson, Lazarsfeld e McPhee, 1954).

Alguns trabalhos tentaram mostrar um lado mais racional dos eleitores norte-americanos. Esse eleitor racional, ainda que ideologicamente inocente, era retrospectivo, altamente punitivo em relação a desempenhos insatisfatórios de seus representantes, mas capaz de "premiar" os resultados positivos (Key, 1966). Apesar desse achado, a concepção do cidadão americano não racional, extremamente falha, dominou o pensamento e as pesquisas durante anos. Somente depois de duas décadas da publicação de The American Voter novos estudos voltaram a demonstrar a existência de um eleitorado atento para as decisões políticas, e desde então tem-se coletado cada vez mais evidências desse tipo de comportamento (Nie, Verba e Petrocik, 1979; Carmines e Stimson, 1989; Alvarez, 1997). Além disso, a literatura mais recente sobre o voto em democracias industriais avançadas aponta para o fato de que os interesses do eleitorado em relação a determinados temas e às políticas públicas têm um papel fundamental na escolha do voto e nos resultados eleitorais (Bay e Mayer, 1993; Dalton, Flanagan e Beck, 1984; Norputh, 1992; Flanagan et alii, 1991; Kitschelt, 1994; Johnston et alii, 1992).

Em muitos aspectos, as pesquisas sobre o comportamento do eleitorado brasileiro na Nova República são similares aos estudos clássicos norte-americanos. Os eleitores brasileiros não parecem ter fortes opiniões sobre assuntos políticos cruciais. E cobrar dos representantes eleitos transparência e responsabilidade pública é algo impensável, uma vez que a maioria dos cidadãos sequer se lembra em quem votou na eleição anterior (Jornal do Brasil, 1998). A maior parte dos testes empíricos sobre associação entre voto e determinado tema da agenda é inconsistente (Kinzo, 1992; Castro, 1994; Singer, 1999). De fato, elites e massas repetem o mantra "o povo não sabe votar".

Um estudo recente descreve o eleitorado brasileiro como "irracional" (Silveira, 1998). O eleitor irracional é geralmente incoerente e desarticulado para tratar de assuntos políticos. As escolhas eleitorais estão baseadas no personalismo, ou seja, nas características próprias do candidato, como honestidade e imagem. Os eleitores raramente optam por um candidato segundo idéias políticas e econômicas, e justificam suas decisões eleitorais com um "eu gostei dele" ou um "ele era o me- 
lhor candidato para o país" (Kinzo, 1992; Baquero, 1994; Castro, 1994; Von Mettenheim, 1995). A quantia de dinheiro gasta em propaganda política e o status de celebridade que alguns marqueteiros possuem atestam a importância da imagem do candidato junto ao eleitorado.

Quando muito, estudiosos argumentam que um pequeno grupo de cidadãos bem-educados e politicamente sofisticados (talvez entre $10 \%$ e 15\% do eleitorado) são os únicos eleitores "racionais" do país (Silveira, 1998; Baquero, 1994; Castro, 1994). Em outras palavras, o voto baseado em temas ou no resultado de políticas públicas acontece somente dentro do espectro de um eleitorado de elite, porque a maior parte dos brasileiros tem um baixo nível de escolarização - nas eleições de 1998, o Tribunal Superior Eleitoral estimou que somente 25\% do eleitorado havia completado pelo menos um ano do $2^{\circ}$ grau (Morães, 1998). Esses estudiosos assumem (ainda que sem evidência empírica) que a educação é um pré-requisito para se ter o discernimento político necessário para conhecer as propostas dos candidatos e também pensar abstrata e prospectivamente sobre a política e seus resultados. Tais crenças sobre o nexo entre educação e "racionalidade" (ou o voto segundo temas), no Brasil, provavelmente, contribuem muitíssimo para o conceito excessivamente popular de que os eleitores brasileiros são menos coerentes, menos voltados para a política do que os cidadãos de democracias mais consolidadas, onde existem eleitorados mais escolarizados.

A predominância do clientelismo nas relações Estado-sociedade no Brasil também está subjacente à percepção de que os cidadãos não politizam temas de importância nacional (Weyland, 1996; Hagopian, 1996; Von Mettenheim, 1995). O clientelismo é a "prática de favores na esfera política e a institucionalização da troca de votos por benefícios particulares realizados por aqueles investidos do poder público" (Diniz, 1982:17). Existentes principalmente nos planos estadual e municipal, os sistemas clientelistas caracterizam-se pela falta de conflito ideológico. O conflito político fica reduzido à disputa por limitados recursos públicos e benefícios pessoais, tais como água potável, ruas limpas, vagas de estacionamento e, sobretudo, empregos no setor público. Ao receberem benefícios públicos, os cidadãos desenvolvem laços com seus chefes políticos. Portanto, embora o voto clientelista seja racional (e economicamente auto-interessado), tais eleitores não estão voltados para os debates políticos, sobretudo aqueles de importância nacional. 
Assim como os primeiros teóricos da escolha racional, alguns estudiosos do comportamento político do eleitorado brasileiro têm tentado "resgatar" o eleitor brasileiro, a partir de um modelo retrospectivo racional. Existem fortes e convincentes evidências de haver um eleitor racional que baseia sua escolha eleitoral na avaliação do desempenho dos políticos enquanto no exercício do cargo. A eleição presidencial de 1994, por exemplo, dificilmente será entendida sem um modelo com tais características, ainda que com uma peculiaridade. Esse modelo presume a existência de um candidato no exercício do cargo ou, no mínimo, de um candidato cujo partido ocupa cargos. Não foi o caso das eleições presidenciais de 1994, mas Fernando Henrique Cardoso, apoiado pelo presidente à época, beneficiou-se dos julgamentos referentes ao seu desempenho como ministro do Planejamento. Durante a campanha, ele desempenhou o papel de "pai do Real", o plano monetário e de estabilização que derrubou a inflação poucos meses antes das eleições. Nesse mesmo período, sua fatia do eleitorado cresceu de 19\% em junho para $47 \%$ em setembro, vencendo as eleições com 53\% de votos válidos (Teixeira Mendes e Venturi, 1994) - diversos estudos demonstraram que o Plano Real foi decisivo para a vitória de Fernando Henrique Cardoso (idem; Meneguello, 1996; Almeida, 1996). O mesmo padrão repete-se no que se refere à aprovação presidencial (Chaffee, 1998). Embora a existência de um padrão de escolha eleitoral baseado na avaliação do desempenho no cargo público possa sustentar idéias de competência democrática do eleitorado brasileiro, ainda é muito diferente do voto orientado por temas (issue voting).

Até o momento, a maior evidência de votos orientados por temas vem de Singer (1999). Seu argumento sustenta que as eleições presidenciais brasileiras de 1989 e 1994 tiveram, no que diz respeito ao eleitorado, uma importante dose de conflito ideológico. De acordo com esse autor, a dimensão ideológica foi definida pelo grau de envolvimento do Estado na sociedade civil e, segundo ele, Collor (1989) e Fernando Henrique (1994) receberam uma quantia desproporcional de votos de brasileiros que gostariam que o Estado interviesse na sociedade civil para manter a ordem, proibindo greves e banindo os partidos comunistas. Lula, o candidato do Partido dos Trabalhadores, recebeu o apoio esmagador de eleitores que não queriam a repressão das mobilizações sociais pelo Estado. Singer explica que, para o eleitorado, essa divisão ideológica não diz respeito à oposição econômica estatistas versus liberais e, mesmo desprezando-se a relação bivaria- 
da, indica como sendo irrelevante em relação às escolhas dos eleitores em 1989 e 1994.

Para verificar se os debates sobre política econômica são politizados pelo eleitorado brasileiro, elaborei um modelo multivariado sobre a aprovação presidencial, utilizando dados de uma pesquisa de janeiro de 1998, a partir de 993 residentes urbanos. Os trabalhos citados até agora são quase exclusivamente estudos sobre o comportamento do eleitorado, uma vez que análises sistemáticas da aprovação presidencial no Brasil são ainda raras. Entretanto, como estou preocupado com o problema mais amplo de verificar se as atitudes com relação a questões econômicas têm peso nas avaliações políticas e no comportamento do eleitorado (i.e., se o conflito em relação às políticas de liberalização do mercado têm sido politizadas), teorias e descobertas de pesquisas sobre comportamento eleitoral aplicam-se ao caso da aprovação presidencial. Além disso, a correlação entre aprovação presidencial e escolha do candidato é bastante elevada, especialmente em eleições com somente dois ou três candidatos viáveis; descobertas e hipóteses encontradas na literatura sobre eleições são, portanto, relevantes e bastante similares (Fiorina, 1981).

\section{DEBATES SOBRE POLÍTICA ECONÔMICA E CONFLITO}

Antes de descrever o modelo multivariado de aprovação presidencial, enumero aqui os temas de política econômica incluídos como variáveis independentes no modelo. Embora as reformas liberalizantes tenham ocorrido em diversas frentes nos anos 90, concentro-me nas seguintes mudanças: livre-comércio, investimento estrangeiro direto e privatização.

O legado mais importante do presidente Collor, a liberalização do comércio, constitui a mais fundamental e importante mudança econômica da década de 90. Por meio da redução unilateral de tarifas e da consolidação do Mercosul, Collor reverteu, em apenas três anos, seis décadas de protecionismo. (De 1987 a 1995, a participação do comércio no PIB aumentou de $17 \%$ para $27 \%$.) Depois de Collor, o presidente Fernando Henrique, na verdade, aumentou as tarifas em alguns setores (p. ex., no setor automotivo), mas a política do seu primeiro mandato de manter a moeda supervalorizada teve um maior efeito liberalizante na economia. Além disso, o presidente tem procurado aprofundar os laços com o Mercosul, além de apoiar entusiasticamen- 
te a Área de Livre-Comércio das Américas - ALCA, que deveria criar uma área de livre-comércio no hemisfério em 2005.

O livre-comércio tem tido bons e maus resultados com Fernando Henrique Cardoso. Décadas de proteção criaram a mais desenvolvida e diversificada base industrial da América Latina, mas também tornaram as empresas locais incapazes de competir segundo padrões internacionais. A rápida liberalização do comércio, combinada com a supervalorização da moeda, foi fatal para centenas de empresas brasileiras ineficientes, que simplesmente não tiveram tempo de ajustar-se à concorrência intensificada pelas importações. Muitas fábricas brasileiras fecharam suas portas ou demitiram funcionários para aumentar sua eficiência, em um processo que contribuiu para que as taxas de desemprego batessem todos os recordes em 1998. Com a redução do parque industrial, milhares de trabalhadores perderam seus empregos, levando a taxa de desemprego em janeiro de 1998 ao patamar de 7,3\% - até então, a mais alta desde o início dos anos 80 . Lula, o candidato à Presidência pelo Partido dos Trabalhadores em 1998, durante sua campanha presidencial associou a perda de empregos com os bens importados, exigindo a redução das importações "predatórias e supérfluas".

Apesar de ser o principal causador do desemprego, o livre-comércio expôs os consumidores a uma maior variedade de bens com maior qualidade e menor preço. De fato, os benefícios do livre-comércio são visíveis para os consumidores a qualquer hora em que vão às compras, e isto pode explicar sua popularidade. No survey utilizado para este trabalho, cerca de $75 \%$ dos entrevistados acreditam que o livre-comércio foi bom ou muito bom para o país. Resumindo, o livre-comércio teve impacto profundo e visível na economia brasileira dos anos 90, especialmente durante o governo Fernando Henrique. Por esse motivo, espero confirmar que a postura do eleitorado sobre o livre-comércio influenciou as avaliações da administração Fernando Henrique.

A explosão de investimentos externos diretos (IEDs) no Brasil teve impacto menos importante, embora substantivo, na economia. O Brasil vinha recebendo investimentos estrangeiros em diversos setores desde o pós-guerra, mas o governo regulava-os severamente com normas sobre remessas de lucros e taxas de repatriação de capitais. Esses controles de mercado caíram na década de 90 e os IEDs aumen- 
taram de US\$ 1 bilhão em 1991 para US\$ 22 bilhões em 1998. Os defensores do livre-comércio afirmam que as empresas de capital estrangeiro radicadas em solo nacional geram reservas e empregos que de outra forma não existiriam, preenchendo o vácuo deixado pela ineficiência ou ausência do investimento local. Seus adeptos também vêem os IEDs como uma fonte mais rica de bens. Por fim, os IEDs atrairiam mais conhecimentos e tecnologias para os países em desenvolvimento, promovendo a eficiência e tornando esses países globalmente competitivos.

Os IEDs, porém, podem ter impacto negativo na área laboral. Firmas estrangeiras que investem no Brasil têm sido mais intensivas em capital do que seus concorrentes locais. Requerem, assim, menos empregados e, se as empresas locais resolvem entrar na concorrência, passam igualmente a demitir funcionários. A longo prazo, os IEDs no setor podem gerar uma perda massiva de empregos - um exemplo: a despeito dos incrementos anuais de IEDs e produtos, os postos de trabalho em fábricas automobilísticas diminuíram 25\% desde 1980 (Fotha de S. Paulo, 1998). Porém, diferentemente do livre-comércio, os IEDs podem ter um impacto positivo em setores não comerciais, tais como o setor financeiro, de seguros, restaurantes e supermercados.

Talvez o mais visível e polêmico componente das reformas liberalizantes da década de 90 seja a privatização. Collor iniciou o programa nacional de privatização no Brasil, mas as mais importantes privatizações, e de longe o maior número delas, aconteceram durante o primeiro governo de Fernando Henrique Cardoso. Em 1998, Fernando Henrique já tinha privatizado a Companhia Vale do Rio Doce CVRD, uma das maiores e mais rentáveis empresas estatais do país, assim como muitos outros monopólios de utilidade pública (água, rodovias e energia elétrica). Em muitos casos, a venda de serviços públicos tornou-se um problema quando os serviços oferecidos pioraram, em vez de melhorar, como os reformistas liberais haviam prometido. Além dos efeitos diretos sobre o consumidor, a privatização contribuiu para o desemprego no Brasil, uma vez que empresas recém-privatizadas passaram a demitir funcionários. Segundo Alcântara (1999), o número de trabalhadores demitidos de empresas estatais na década de 90 supera a casa dos 100 mil. O lado positivo é que as indústrias recém-privatizadas aumentaram rapidamente sua eficiência e margens de lucro, e os recursos auferidos com a venda das empresas estatais têm sido usados para abater o déficit governamental. 
A privatização, além de ter gerado ganhadores e perdedores, é objeto de um debate ideológico polarizado. Mesmo não existindo nenhuma ameaça militar externa, os opositores da privatização enxergam a venda de estatais que atuam em setores "estratégicos" (telecomunicações, extração mineral e petróleo) a investidores estrangeiros como uma ameaça à segurança nacional. Eles também criticam a venda do "patrimônio do povo" às burguesias nacional e internacional. Os defensores das reformas replicam dizendo que somente uma pequena porcentagem das estatais privatizadas era lucrativa, e, portanto, a maior parte delas só contribuía para o aumento da dívida pública. Advogam também que o governo não possui mais condições de investir em muitos dos setores em que antes atuavam as empresas estatais. Em outras palavras, a privatização permitirá que o Estado invista mais na área social, abrindo espaço para que o investimento privado, mais abundante, torne as indústrias recém-privatizadas preparadas para o mercado global.

Dos três temas que utilizei na construção do modelo de aprovação presidencial, a privatização foi o mais contestado pela elite. A esquerda opôs-se a todas as privatizações, quando estas aconteceram. Muitas das maiores privatizações, como as da USIMINAS, TELEBRAS e CVRD, foram acompanhadas por manifestações populares e por violência, além de contestadas por vias legais. Na campanha eleitoral de 1998, Lula prometeu congelar o programa nacional de privatização e cancelar as privatizações corruptas. Em resumo, por causa da divisão nas elites, pelo conteúdo ideológico e pelo seu recente impacto na economia, sugiro que a privatização seja uma clivagem central no que diz respeito ao comportamento político das massas.

\section{DADOS E RESULTADOS BIVARIADOS}

Antes de descrever o modelo multivariado de aprovação presidencial, enumero aqui os itens do survey usados para medir as opiniões do eleitorado sobre assuntos econômicos, e apresento algumas relações bivariadas interessantes. Os resultados vêm da pesquisa do The Wall Street Journal Americas, "Mirror of the Americas", de janeiro de 1998 (Schumacher, 1998), para a qual o Instituto Vox Populi realizou 993 entrevistas, sendo a amostra representativa da população urbana brasileira. Os três itens que medem as posturas diante de certos assuntos são variáveis ordinais. Os valores maiores indicam maior apoio a uma determinada política ${ }^{1}$. Cada variável também tem uma 
categoria intermediária que contempla entrevistados indiferentes (sem resposta ou "não sabe, não opina") ou ambivalentes. As distribuições univariadas encontram-se na Tabela 1. A privatização é um tema bastante polarizado para o eleitorado brasileiro, enquanto o livre-comércio e o investimento estrangeiro direto têm uma inclinação positiva. No geral, a população parece ser levemente favorável às reformas de liberalização do mercado implementadas por Collor e Fernando Henrique. No entanto, uma minoria substancial da população é contrária à privatização e ao investimento estrangeiro direto.

Tabela 1

Distribuição Univariada de Questões de Política Econômica (as entradas são a porcentagem da amostragem)

\begin{tabular}{l|c|c|c}
\hline & Contra & Indiferente ou Ambivalente & A Favor \\
\hline Livre-comércio & 17 & 9 & 73 \\
IED & 35 & 16 & 49 \\
Privatização & 41 & 21 & 38 \\
\hline
\end{tabular}

Fonte: The Wall Street Journal Americas, "Mirror on the Americas" survey, 1998.

Até que ponto as opiniões acerca das políticas de mercado exibem uma dimensionalidade ou um issue constraint? (Converse, 1964) Estudiosos do comportamento político normalmente interpretam correlações altas entre crenças quanto a diferentes temas políticos como um sinal de sofisticação e abstração política. Se as correlações entre as crenças sobre livre-comércio, investimento estrangeiro direto e privatização são altas no Brasil, então as opiniões sobre cada política estarão provavelmente estruturadas em compromissos subjacentes com uma estratégia de desenvolvimento econômico estatal ou liberal. As correlações entre itens da Tabela 2 indicam a existência de uma fraca dimensão econômica a determinar as opiniões sobre cada uma das três políticas. Em outras palavras, há um caráter estatista, ou liberal, estruturando as posturas acerca de políticas econômicas particulares - por exemplo, defensores do livre-comércio tendem a apoiar mais a privatização que aqueles contrários à mesma. A existência de tal relação indica que são exagerados os modelos que ressaltam a incoerência e a incapacidade dos brasileiros para agrupar várias idéias políticas e econômicas (Silveira, 1998). No entanto, como indica o relativamente baixo coeficiente de correlação (apesar de estatisticamente significante), esse tipo de pensamento ideológico e unidimensional acontece até certo ponto. 
Reformas Liberalizantes e Aprovação Presidencial: A Politização...

Tabela 2

Correlações entre Itens de Opinião (por tema)

\begin{tabular}{l|c|c}
\hline & IED & Privatização \\
\hline Livre-comércio & 0,265 & 0,223 \\
IED & & 0,181 \\
\hline
\end{tabular}

Fonte: The Wall Street Journal Americas, "Mirror on the Americas" survey, 1998.

Até que ponto, então, as opiniões sobre políticas econômicas são politizadas entre os cidadãos comuns? A Tabela 3, que faz uma tabulação cruzada da aprovação presidencial com três variáveis relacionadas à economia, reforça o argumento sobre a presença de alguma coerência e racionalidade dos brasileiros quanto ao pensamento político. A aprovação presidencial é uma variável ordinal que vai de 1 a 5, cujos valores aumentam conforme o apoio dado a Fernando Henrique Cardoso $^{2}$. Nas relações bivariadas, as opiniões sobre a economia têm peso político: as concepções sobre a política econômica brasileira influenciam as avaliações do presidente no cargo. $O$ fato de o apoio aumentar da esquerda para a direita em cada uma das linhas indica que à medida que a pessoa vai se tornando mais liberal em cada item, a avaliação do presidente melhora. Dada a atuação de Fernando Henrique em cada um desses aspectos da reforma liberalizante, tais relações se encontram na direção esperada.

Tabela 3

Relações Bivariadas entre Aprovação Presidencial e Opiniões (por tema)

(as entradas são a média de cada grupo da variável aprovação presidencial)

\begin{tabular}{l|c|c|c}
\hline & Contra & Indiferente ou Ambivalente & A Favor \\
\hline Livre-comércio & 2,55 & 2,84 & 3,30 \\
IED & 2,81 & 3,19 & 3,35 \\
Privatização & 2,71 & 3,09 & 3,61 \\
\hline
\end{tabular}

Fonte: The Wall Street Journal Americas, "Mirror on the Americas" survey, 1998.

\section{Resultados Multivariados}

Os resultados bivariados só trazem evidências preliminares da racionalidade no pensamento político do eleitorado brasileiro. Para controlar fatores que possam confundir e para evitar as armadilhas potenciais de uma correlação espúria, esmiucei e calculei um modelo multivariado de aprovação presidencial. Uma vez que a variável dependente (de cinco categorias) é ordinal, um modelo probit ordenado torna-se apropriado no caso multivariado. Especifiquei o modelo 
com dois tipos de variáveis. O principal grupo de interesse contém as três questões econômicas descritas acima. Se os brasileiros são racionais, então os coeficientes dessas variáveis devem ser positivos, indicando que quanto menos estatistas as pessoas se manifestam em um item, mais favoráveis serão na avaliação do governo de Fernando Henrique Cardoso.

O segundo grupo de variáveis independentes é um conjunto de características demográficas que incluem gênero, renda, educação, tamanho da cidade e faixa etária. A forma como as clivagens sociais e de classe se traduzem em conflito político é bastante instável no Brasil. Em muitos casos, as relações entre classe e voto foram bastante fracas. Na eleição de 1989, apesar de os pobres e aqueles com um nível educacional inferior terem ficado menos inclinados a escolher o estatista Lula e sim o neoliberal Collor, essa relação entre classe e comportamento eleitoral desapareceu em 1994 (Moisés, 1993). Na eleição de 1994, a renda do eleitor não teve praticamente relação alguma com a escolha do candidato a presidente e aqueles com um nível educacional inferior apresentaram leve preferência por Fernando Henrique Cardoso (Meneguello, 1996). Incluí a renda e o nível de educação como variáveis independentes, embora esperando que o impacto dessas variáveis fosse baixo ou nulo ${ }^{3}$.

Durante a campanha eleitoral de 1998, os marqueteiros de Fernando Henrique Cardoso reconheceram a falta de apoio junto ao eleitorado feminino, promovendo então tentativas de aumentar o apoio desse grupo. Assim, esperei que o gênero do entrevistado tivesse um impacto importante na aprovação presidencial. O modelo também incluiu a faixa etária do entrevistado, levantando a hipótese de que pessoas mais velhas são mais conservadoras e aprovam as posições conservadoras de Fernando Henrique. Finalmente, o modelo conteve uma medida da população da cidade do entrevistado ${ }^{4}$. Chefes políticos clientelistas, altamente conservadores e que poderiam apoiar Fernando Henrique, prevalecem e são mais poderosos nas pequenas cidades. Além disso, partidos de oposição ao governo e organizações sociais são muito mais estruturados em áreas urbanas. Esse padrão poderia levar a uma maior taxa de aprovação de Fernando Henrique nas pequenas cidades.

A Tabela 4 exibe os coeficientes integrais ordenados para o modelo completo. Os resultados do modelo multivariado demonstram clara- 
mente a relação entre posturas com relação a certos temas e aprovação presidencial. Os coeficientes para as três variáveis temáticas encontram-se na direção esperada e são estatisticamente significantes, indicando que a aversão às políticas de livre mercado implementadas por Fernando Henrique Cardoso leva algumas pessoas a avaliarem sua administração negativamente. Algumas das variáveis demográficas antecipam também prognósticos sobre a aprovação presidencial. As mulheres são significativamente menos entusiásticas em relação a Fernando Henrique do que os homens. O apoio a ele aumenta com a idade, mas é muito menor nas grandes cidades do que nas menores. Renda e nível de escolaridade não têm relação estatisticamente significante com a aprovação presidencial.

Tabela 4

Modelo Multivariado de Aprovação do Governo Fernando Henrique Cardoso (as entradas são estimadores de probit ordenado)

\begin{tabular}{l|c|c}
\hline N=973 & Estimadores de Probit Ordenado & Erros-Padrão \\
\hline Livre-comércio & $0,17^{* *}$ & 0,03 \\
Investimento estrangeiro direto & $0,11^{* *}$ & 0,04 \\
Privatização & $0,28^{* *}$ & 0,04 \\
Ln (Idade) & $0,20^{*}$ & 0,10 \\
Tamanho da cidade & $-0,10^{*}$ & 0,05 \\
Mulher & $-0,29^{* *}$ & 0,07 \\
Educação & $-0,00$ & 0,04 \\
Renda & $-0,03$ & 0,04 \\
Constante & $0,94^{*}$ & 0,39 \\
\hline
\end{tabular}

Fonte: The Wall Street Journal Americas, "Mirror on the Americas" survey, 1998.

Obs.: Pseudo- $R^{2}=0,14^{5}$.

${ }^{*} \mathrm{p}<0,05$

${ }^{* *} \mathrm{p}<0,01$

Interpretados sozinhos, os coeficientes em modelos de probit ordenado nem sempre expressam um retrato claro dos efeitos relativos e totais das variáveis independentes. Nesse caso, as representações gráficas costumam ser úteis para explicitar o grau de relação entre as variáveis. A Figura 1 mostra o impacto das variáveis de postura sobre política econômica. A figura delineia a probabilidade predita por onze indivíduos hipotéticos, gerados a partir dos resultados da Tabela 4, de classificação do governo de Fernando Henrique Cardoso como sendo "bom" ou "muito bom". Esses onze indivíduos são todos mulheres que compartilham valores idênticos, medianos em todas as 
outras variáveis independentes exceto nas posições sobre os três temas já relacionados. Em outras palavras, todas as onze mulheres são de classe média baixa, têm oito anos de escolaridade, 36 anos de idade e moram em uma cidade com mais de um milhão de habitantes. Não existe nada inerentemente peculiar nesse tipo de pessoa, à qual, para facilitar a exposição, me referirei como "mulher mediana". No entanto, é necessário manter essas variáveis constantes para avaliar o impacto causal independente das variáveis temáticas. Escolhi as medianas justamente para demonstrar o impacto das variáveis temáticas em uma pessoa "típica".

Apesar de compartilharem dessas características demográficas, as onze mulheres hipotéticas diferem entre si nas suas opiniões quanto a temas. Por exemplo, na Figura 1, os três pontos da linha intitulada "privatização" mostram as probabilidades de uma avaliação positiva de Fernando Henrique Cardoso para três dos indivíduos hipotéticos que diferem somente em suas posturas sobre privatização (as duas outras variáveis temáticas permanecem constantes em suas médias). Em outras palavras, uma mulher mediana que é contra a privatização tem probabilidade de 0,37 de dizer que Fernando Henrique Cardoso é bom ou muito bom como presidente, enquanto uma mulher com as mesmas características, mas a favor da privatização, tem uma probabilidade de 0,59 de aprovar o presidente. Portanto, essa linha traça o impacto independente das posturas sobre privatização, porque todas as outras variáveis estão constantes ${ }^{6}$. As outras duas linhas podem ser interpretadas da mesma forma, substituindo a política indicada nas mesmas. $\mathrm{O}$ fato de que as linhas são ascendentes no sentido esquerda-direita indica que o apoio a Fernando Henrique Cardoso aumenta quando aumenta o apoio para os tipos de políticas por ele implementadas. No geral, o investimento estrangeiro direto parece ter a menor influência, enquanto a privatização e o livre-comércio têm um impacto bastante forte na aprovação presidencial.

Finalmente, os dois pontos na Figura 1 que não estão ligados através de linhas representam as probabilidades para dois tipos finais de mulher mediana. O círculo preto retrata um "extremo estatista", ou uma mulher mediana contra o livre-comércio, o investimento estrangeiro direto e a privatização. O losango preto indica uma "extremo liberal", ou uma mulher mediana favorável ao livre-comércio, ao investimento estrangeiro direto e à privatização. A diferença extrema de proba- 
Reformas Liberalizantes e Aprovação Presidencial: A Politização...

Figura 1

Os Efeitos das Atitudes Político-Econômicas

na Aprovação Presidencial

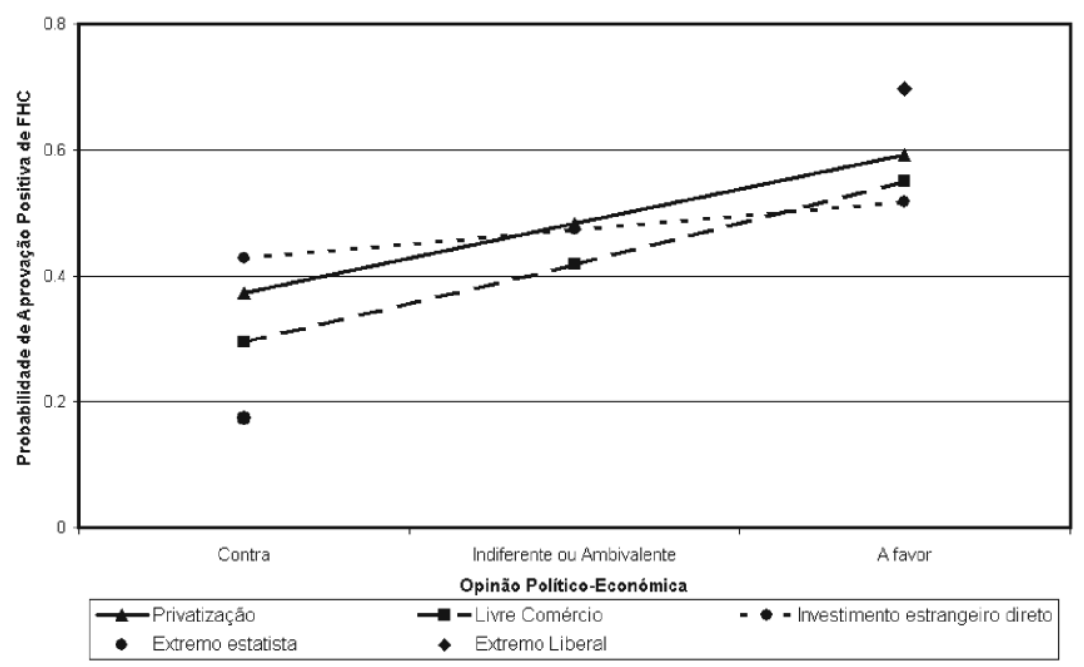

bilidades entre esses dois pontos $(0,17$ contra 0,70$)$ representa o grande impacto conjunto das três variáveis de opinião política.

Essa figura demonstra claramente o amplo grau em que as posturas sobre a reforma econômica no Brasil estão politizadas. No lugar de posições incoerentes e aleatórias sobre importantes temas econômicos, os brasileiros associam suas opiniões sobre política econômica ao reino da política, baseando nessas opiniões seus julgamentos sobre o presidente em exercício. Além disso, as avaliações do presidente vão muito além de suas características pessoais e do desempenho da economia sob sua administração, diferentemente do que a literatura existente possa nos levar a crer. De fato, os padrões da Tabela 4 e da Figura 1 indicam os seguintes elementos de comportamento político no eleitorado brasileiro:

1. Muitas pessoas têm consciência dos debates sobre política econômica existentes e têm posturas bem definidas em relação a questões econômicas de importância nacional.

2. Muitos também estão conscientes da postura real e objetiva do presidente nessas questões. 
3. Dado os primeiros dois elementos, muitos brasileiros avaliam o presidente de acordo com a implementação dos tipos de política que eles, brasileiros, apóiam.

Uma pergunta: é possível que esses resultados não se apliquem a todos os cidadãos? Como mencionado, há consenso entre os estudiosos de que os eleitores brasileiros com nível mais alto de escolaridade são mais coerentes em suas concepções sobre política econômica, e também mais racionais e mais atentos para as questões de política pública (Silveira, 1998). Esta proposição pode ser facilmente testada a partir dos dados e técnicas usados ao longo deste artigo. Para avaliar a hipótese de coerência quanto a concepções sobre determinadas políticas, a Tabela 5 tabula a correlação média entre os três temas de política econômica por quatro categorias educacionais. Se os cidadãos com educação superior tiverem posições mais coerentes sobre as políticas econômicas assinaladas, as entradas deverão aumentar na mesma medida que o nível educacional. A Tabela 5 mostra claramente que esse não é o caso, uma vez que as posturas entre os menos escolarizados apresentam uma correlação tão alta quanto entre os cidadãos com maior escolaridade.

Tabela 5

Correlação Média entre as Três Questões Temáticas, segundo a Escolarização

\begin{tabular}{l|c|c|c|c}
\hline & $\mathbf{0}$ a $\mathbf{4}$ anos & $\mathbf{5}$ a $\mathbf{8}$ anos & $\mathbf{9}$ a $\mathbf{1 1}$ anos & $\begin{array}{c}\text { Estudos } \\
\text { Superiores }\end{array}$ \\
\hline Correlação média entre itens & 0,240 & 0,215 & 0,125 & 0,285 \\
\hline
\end{tabular}

Fonte: The Wall Street Journal Americas, "Mirror on the Americas" survey, 1998.

Para testar se os brasileiros com um nível mais baixo de escolarização são menos "racionais", ou menos atentos para determinados temas da agenda em suas avaliações políticas, elaborei outro modelo de probit ordenado similar àquele da Tabela 4. Entretanto, desta vez estimei dois conjuntos de coeficientes para cada variável temática. Um destes se refere ao efeito da variável no grupo mais escolarizado da população, enquanto o outro diz respeito ao mesmo efeito desse fator no grupo menos escolarizado da população. Ou seja, a comparação entre o impacto de uma mesma variável em dois grupos distintos é obtida pela simples divisão desse grupo em dois subconjuntos. A variável para a porção menos escolarizada da população é simplesmente registrada como zero para todos os casos em que cair na metade mais escolarizada da amostra. O inverso é feito para o grupo com educação superior. O corte 
é "alguma educação superior". Aqueles com pelo menos um ano de faculdade (aproximadamente 20\% da amostra) situam-se entre os "mais escolarizados", enquanto todos os outros caem na categoria de menos escolarizados. Se os temas tiverem impactos que dependam da escolarização, os dois coeficientes serão estatisticamente diferenciáveis. $\mathrm{O}$ senso comum sobre o eleitorado brasileiro indica que os coeficientes para eleitores com menor escolaridade serão estatisticamente indiferenciáveis de zero $e$ serão estatisticamente diferentes do coeficiente referente à população mais escolarizada.

Os resultados não apóiam o senso comum em nenhum dos três casos, e padrões diferentes prevalecem para cada tema. As posturas sobre o livre-comércio têm influência mais forte e estatisticamente significante entre os menos escolarizados.

Tabela 6

Segundo Modelo Multivariado de Aprovação Presidencial: Teste para Efeitos

Heterogêneos de Opiniões quanto a Temas de Política Econômica, segundo Nível Educacional

(as entradas são estimadores de probit ordenado)

\begin{tabular}{l|c|c}
\hline N=973 & $\begin{array}{c}\text { Estimadores } \\
\text { de Probit } \\
\text { Ordenado }\end{array}$ & $\begin{array}{c}\text { Erros- } \\
\text { Padrão }\end{array}$ \\
\hline Livre-comércio (nenhum ano de ensino superior) & $0,18^{* *}$ & 0,03 \\
Livre-comércio (pelo menos um ano de ensino superior) & 0,10 & 0,07 \\
IED (nenhum ano de ensino superior) & $0,09^{*+}$ & 0,04 \\
IED (pelo menos um ano de ensino superior) & $0,27^{* *^{+}}$ & 0,10 \\
Privatização (nenhum ano de ensino superior) & $0,28^{* *}$ & 0,04 \\
Privatização (pelo menos um ano de ensino superior) & $0,24^{* *}$ & 0,09 \\
Ln (idade) & $0,20^{*}$ & 0,10 \\
Tamanho da cidade & $-0,10^{*}$ & 0,05 \\
Mulher & $-0,29^{* *}$ & 0,07 \\
Educação & $-0,00$ & 0,05 \\
Renda & $-0,03$ & 0,04 \\
Constante & $0,90^{*}$ & 0,39 \\
\hline
\end{tabular}

Fonte: The Wall Street Journal Americas, "Mirror on the Americas" survey, 1998.

Obs.: Pseudo- $\mathrm{R}^{2}=0,14$.

${ }^{*} \mathrm{p}<0,05$

** $\mathrm{p}<0,01$

$\dagger=$ alguma faculdade

Coeficiente $-=$ nenhuma faculdade

Coeficiente $\neq 0$

De fato, o impacto é mais que o dobro nesse grupo e quase desprezível entre os mais escolarizados. Os coeficientes na variável IED são os 
que chegam mais perto de reforçar o senso comum, uma vez que os menos escolarizados estão muito menos inclinados a avaliar o presidente Fernando Henrique Cardoso usando esse critério. No entanto, o coeficiente entre aqueles que nunca freqüentaram uma faculdade é ainda estatisticamente significante. Também se registre que a privatização tem impacto bastante expressivo e igual na politização dos dois grupos. Em suma, não existem evidências para validar o senso comum de que os brasileiros menos escolarizados são menos racionais e coerentes na hora de avaliarem seu presidente.

\section{CONCLUSÃO}

Como os cidadãos norte-americanos das décadas de 50 e 60, os eleitores brasileiros têm sido apontados pelos estudiosos de comportamento como desatentos, pouco sofisticados e irracionais no que tange a suas avaliações políticas e seu comportamento também político. Em virtude da, infelizmente, baixa escolarização do eleitorado, bem como dos arranjos clientelistas nas relações Estado-sociedade, muitos estudiosos, freqüentemente sem evidências empíricas suficientes, argumentam que os brasileiros são seres políticos altamente irracionais, que só enxergam as características pessoais dos candidatos ou benefícios particularistas. Esse quadro contrasta significativamente com os dados atuais sobre eleitores em democracias industriais avançadas, os quais são atentos a temas da agenda pública.

Os resultados deste artigo demonstram que os brasileiros parecem ser tão atentos às políticas públicas quanto os eleitores - mais escolarizados - da América do Norte e da Europa Ocidental. Pelo menos no que diz respeito às avaliações do presidente, muitos brasileiros são altamente racionais, uma vez que (1) são coerentes em suas convicções sobre política econômica; (2) conhecem as convicções do seu presidente; (3) avaliam-no segundo o grau de aproximação entre as políticas por ele apresentadas e as suas próprias convicções. Além disso, contrariamente às percepções de vários estudiosos, os brasileiros menos escolarizados não são menos coerentes ou racionais do que os cidadãos mais escolarizados. Pesquisas futuras sobre o comportamento político do eleitorado brasileiro devem levar em conta as demandas dos cidadãos brasileiros relacionadas a temas da agenda política.

(Recebido para publicação em novembro de 1999)

(Versão final traduzida em novembro de 2001) 


\section{Reformas Liberalizantes e Aprovação Presidencial: A Politização...}

\section{NOTAS}

1. Enunciado das questões:

Livre-comércio: "Nos últimos anos, o país tem assistido um crescimento cada vez maior do comércio com outros países. Esta tendência é chamada de 'livre comércio'. Você acha que o livre comércio é bom ou ruim para o país? Muito ou pouco? (1) Muito ruim, (2) Ruim, (3) Sem resposta, (4) Bom, (5) Muito Bom." Para facilitar a comparação com os outros dois assuntos, as categorias (1) e (2) são agrupadas e (4) e (5) agrupam-se nas Tabelas 1 e 3 e na Figura 1.

Investimento Externo Direto: "Qual frase mais se assemelha ao seu modo de pensar? (2) O investimento externo é bom porque ajuda no crescimento econômico, (0) [O investimento externo] é ruim porque a nossa economia fica influenciada pelas ações de outros países, (1) Ambos, Nenhum ou Sem resposta."

Privatização: "Você acha que a privatização é boa ou ruim para o país? (0) Ruim, (1) Depende, Bom e Ruim ou Sem resposta, (2) Bom."

2. A variável de aprovação presidencial, usada como variável dependente na análise multivariada, é a seguinte: "Em geral, que opinião você tem do Presidente Fernando Henrique Cardoso? Boa ou ruim? Muito ou pouco?"

As respostas foram codificadas como segue: (1) muito ruim, (2) ruim, (3) neutro, (4) bom, (5) muito bom. Houve 20 sem resposta.

3. A educação é codificada como número de anos de escolaridade, até o número de 12. Além dos 12, (13)=Faculdade Incompleta, (14)=Faculdade Completa, (15)=Pós-Graduação Incompleta, (16)=Pós-Graduação Completa. A renda é codificada como se segue: (1) Classe Baixa (a base, 40\% da população), (2) Média e Média Baixa (30\% seguintes), (3) Média Alta (20\% seguintes), (4) Alta (o topo, 10\%). Cinqüenta e cinco casos sem resposta para estas duas variáveis imputaram valores usando o algoritmo Emis, desenvolvido por King et alii (2001). As estimativas integrais ordenadas apresentadas nas Tabelas 4 e 6 foram calculadas através da média de mais de nove conjuntos com imputações diferentes para os valores ausentes.

4. O tamanho de cidade foi codificado como se segue: (0) Cidade Pequena (15.000 a 50.000), (1) Cidade Média (50.000 a 100.000), (2) Cidade Grande (100.000 a 1 milhão), (3) Metrópole (mais de 1 milhão).

5. Os modelos integrais ordenados não produzem estatísticas de $\mathrm{R}^{2}$ comparáveis àquelas no modelo clássico de regressão linear. Eu registro pseudo- $\mathrm{R}^{2}$ com reserva para dar uma idéia da discrepância explicada, ressaltando que o valor máximo dessa estatística é um valor indeterminado menor que um. O modelo integral ordenado também produz estimativas das distâncias entre categorias nas variáveis dependentes, mas eu não as mostro aqui.

6. Embora eu descreva esses pontos diferentes como representando probabilidades para pessoas diferentes, pode-se também considerar a mudança nas probabilidades como o impacto de uma alteração na postura do indivíduo. 


\section{Andy Baker}

\section{REFERÊNCIAS BIBLIOGRÁFICAS}

ALCÂNTARA, Eurípedes. (1999), “A Vida Globalizada”. Veja, 27 de janeiro, pp. 48-53.

ALMEIDA, Jorge. (1996), Como Vota o Brasileiro. São Paulo, Casa Amarela.

ALVAREZ, R. Michael. (1997), Information and Elections. Ann Arbor, University of Michigan Press.

BAQUERO, Marcelo. (1994), “O Desencanto com a Democracia: Análise do Comportamento dos Gaúchos nas Eleições de 1994". Opinião Pública, vol. 2, no 2, pp. 49-60.

BAY, Daniel e MAYER, Nonna (eds.). (1993), The French Voter Decides. Ann Arbor, University of Michigan Press.

BERELSON, Bernard, LAZARSFELD, Paul e MCPHEE, William. (1954), Voting. Chicago, University of Chicago Press.

CAMPBELL, Angus, CONVERSE, Philip E., MILLER, Warren E. e STOKES, Donald. (1960), The American Voter. New York, Wiley Press.

CARMINES, Edward G. e STIMSON, James A. (1989), Issue Evolution: Race and the Transformation of American Politics. Princeton, Princeton University Press.

CASTRO, Mônica Mata Machado de. (1994), Determinantes do Comportamento Eleitoral - A Centralidade da Sofisticação Política. Tese de Doutorado, IUPERJ, Rio de Janeiro.

CHAFFEE, Albert. (1998), Desenvolvimento: Politics and Economy in Brazil. Boulder, Lynne Rienner Publishers.

CONVERSE, Philip E. (1964), "The Nature of Belief Systems in Mass Publics", in D. E. Apter (ed.), Ideology and Discontent. New York, Free Press.

DALTON, Russell J., FLANAGAN, Scott e BECK, Paul Allen. (1984), Electoral Change in Advanced Industrial Democracies: Realignment or Dealignment? Princeton, Princeton University Press.

DINIZ, Eli. (1982), Voto e Máquina Política: Patronagem e Clientelismo no Rio de Janeiro. Rio de Janeiro, Paz e Terra.

FIORINA, Morris. (1981), Retrospective Voting in American National Elections. New Haven/London, Yale University Press.

FLANAGAN, Scott C., KOHEI, Shinsaku, MIYAKE, Ichiro, RICHARDSON, Bradley M. e WATANUKI, Joji. (1991), The Japanese Voter. New Haven, Yale University Press.

FOLHA DE S. PAULO. (1998), “Produção de Carros É a Menor desde o Mês de Janeiro de 93 ", 8 de dezembro, pp. 2-5.

HAGOPIAN, Frances. (1996), Traditional Politics and Regime Change in Brazil. Cambridge, University of Cambridge Press.

JOHNSTON, Richard, BLAIS, André, BRADY, Henry e CRÊTE, Jean. (1992), Letting the People Decide: The Dynamics of a Canadian Election. Stanford, Stanford University Press.

JORNAL DO BRASIL. (1998), "Eleitor Ignora Deputados", 5 de julho. 


\section{Reformas Liberalizantes e Aprovação Presidencial: A Politização...}

KEY, V. O. (1966), The Responsible Electorate: Rationality and Presidential Elections, 1936-1960. Cambridge, Harvard University Press.

KING, Gary, HONAKER, James, JOSEPH, Anne e SCHEVE, Kenneth. (2001), “Analyzing Incomplete Political Science Data: An Alternative Algorithm for Multiple Imputation". American Political Science Review, vol. 95, no 1, pp. 49-70.

KINZO, Maria D'Alva Gil. (1992), “A Eleição Presidencial de 1989: O Comportamento Eleitoral em uma Cidade Brasileira". Dados, vol. 35, nำ1, pp. 49-66.

KITSCHELT, Herbert. (1994), The Transformation of European Social Democracy. Cambridge, Cambridge University Press.

LAZARSFELD, Paul, BERELSON, Bernard e GAUDET, Hazel. (1944), The People's Choice. New York, Columbia University Press.

LIMONGI, Fernando e FIGUEIREDO, Argelina Cheibub. (1995), “Partidos Políticos na Câmara dos Deputados: 1989-1994”. Dados, vol. 38, n 3, pp. 497-525.

MAINWARING, Scott, MENEGUELLO, Rachel e POWER, Timothy. (2000), “Conservative Parties, Democracy, and Economic Reform in Contemporary Brazil", in K. J. Middlebrook (org.), Conservative Parties, the Right, and Democracy in Latin America. Baltimore, The Johns Hopkins University Press.

MENEGUELLO, Rachel. (1996), “Electoral Behavior in Brazil: The 1994 Presidential Elections". International Social Science Journal, vol. 147, pp. 627-641.

MOISÉS, José Alvaro. (1993), "Elections, Political Parties and Political Culture in Brazil: Changes and Continuities". Journal of Latin American Studies, vol. 25, nº 4, pp. 575-611.

MORÃES, Marcelo de. (1998), "Mapa do TSE Revela um País Quase Analfabeto". Estado de São Paulo, 12 de agosto.

NIE, Norman, VERBA, Sidney e PETROCIK, John R. (1979), The Changing American Voter. Cambridge, Harvard University Press.

NORPUTH, Helmet. (1992), Confidence Regained: Economics, Mrs. Thatcher and the British Voter. Ann Arbor, University of Michigan Press.

SCHUMACHER, Edward. (1998), "A Meeting of the Minds, from Peoria to Patagonia: Poll Finds Yanks and Latins Often Agree on Trade, Security and Drugs". The Wall Street Journal, 16 de abril, A19.

SILVEIRA, Flavio Eduardo. (1998), A Decisão do Voto no Brasil. Porto Alegre, EdIPUCRS.

SINGER, André Vitor. (1999), Esquerda e Direita no Eleitorado Brasileiro: A Identificação Ideológica nas Disputas Presidenciais de 1989 e 1994. São Paulo, EDusP.

TEIXEIRA MENDES, Manuel Antonio e VENTURI, Gustavo. (1994), “Eleição Presidencial: O Plano Real na Sucessão de Itamar Franco". Opinião Pública, vol. 2, no 2, pp. 39-48.

VON METTENHEIM, Kurt. (1995), The Brazilian Voter: Mass Politics in Democratic Transition, 1974-1986. Pittsburgh, Pittsburgh University Press.

WEYLAND, Kurt. (1996), Democracy without Equity: Failures of Reform in Brazil. Pittsburgh, University of Pittsburgh Press. 


\section{Andy Baker}

\section{ABSTRACT}

Free-Market Reform and Presidential Approval: The Politicization of Economic Policy Debates in Brazil

To date, political scientists have argued that Brazilians' attitudes about neoliberal reforms play no role in mass political behavior or political assessments. In this paper, I provide evidence that Brazilians do politicize economic policy debates. Data from a January 1998 survey demonstrate that mass attitudes about privatization, foreign direct investment and free trade influenced citizens' evaluations of the Fernando Henrique Cardoso presidency. Moreover, there is no evidence to support the conventional wisdom that less educated Brazilians are less rational and coherent when it comes to evaluating their president.

Key words: economic policy; neoliberal reforms; political assessments; political behavior; electorate

\section{RÉSUMÉ}

Réformes Libéralisantes et Approbation Présidentielle: La Politisation des Débats de la Politique Économique au Brésil

Jusqu'à nos jours, les experts politiques soutiennent que l'avis des Brésiliens au sujet des réformes néolibérales n'ont pas d'influence sur le comportement politique ni sur l'évaluation politique de la part des électeurs. Dans cet article, l'auteur veut montrer que, au contraire, les Brésiliens politisent les débats sur la politique économique. Les données d'un survey effectué en janvier de 1998 montrent que les attitudes de l'électorat à propos de la privatisation, des investissements étrangers et de la libéralisation du marché ont eu une influence sur l'évaluation de l'action présidentielle de Fernando Henrique Cardoso. Par ailleurs, il n'y a pas de preuves entérinant l'idée habituelle selon laquelle les Brésiliens peu scolarisés sont moins rationnels et cohérents lors de l'évaluation de leur président.

Mots-clé: politique économique; réformes néolibérales; évaluation politique; comportement politique; électorat 